\title{
Creative Commons ponders share options
}

\section{Paula Gould, London}

A not-for-profit organization is preparing to launch a form of science licensing that it says will give researchers more flexibility when they publish and share data.

The project, called Science Commons, has grown out of the Creative Commons movement, a scheme devised by Lawrence Lessig of Stanford Law School, California, to promote the online publishing of audio, visual and textual materials with "some rights reserved".

Science Commons aims to provide a form of legal protection that could serve as an alternative to both copyright and patents. If successful, the system should allow the creators of a pesticide, for example, to restrict its free use to the developing world through one simple licence, rather than a web of international patents. Most would declare this a worthy goal, but sceptics say it will be a hard slog for Science Commons, as those involved have little experience of patent law.

Creative Commons licences are free to use and legally binding. To date they have garnered most support from musicians and web loggers who wish to promote their work over the Internet, but who do not want to lose all control over its use. The movement's activities are funded primarily by three US-based private foundations, and are

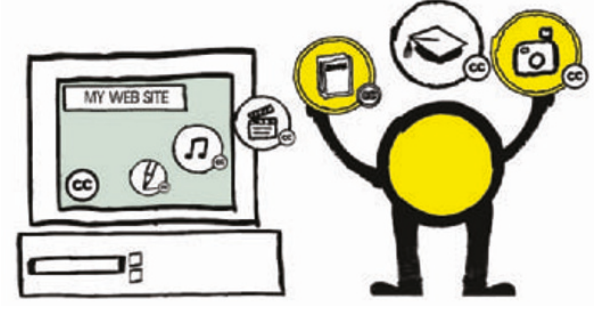

Rights issue: Science Commons would provide legal protection for work published on the web.

run from premises at Stanford Law School.

Since its inception, the movement's founders have wanted to expand into the world of science. Additional funding to do so has now been obtained from an unnamed source. John Wilbanks, a fellow at the World Wide Web Consortium, an organization that aims to promote the development of the web, has been appointed director of Science Commons. He plans to consult with scientists, companies and funding agencies to work out a mechanism by which the commons will work. "We are not coming in with a pre-written agenda. We only want to solve areas of legal friction that the scientific community tells us are a problem,"Wilbanks says.

The "some rights reserved" philosophy has already made inroads into the world of science. A Creative Commons licence covers the content of the Public Library of Science publications PLoS Biology and PLoS Medicine. And the Biological Innovation for Open Science (BIOS) initiative, run by Richard Jefferson, aims to make methods and techniques developed by scientists freely available, in return for the results gained through such techniques also being freely released (see Nature 431, 494; 2004). Science Commons says it hopes to cover all this ground.

Wilbanks is in discussions with BIOS to explore possible link-ups. But Jefferson is sceptical of the impact that Science Commons will have outside the publishing arena. "The world of patents and science has almost nothing to do with the world of copyright. The economics, the culture and the pragmatics have almost no parallels," he says.

Science Commons will initially focus on biomedical sciences when it launches in January 2005. But Wilbanks would ultimately like to see the concept used in a wide range of scientific fields, including astrophysics and high-energy physics, where large amounts of data are collected. "The goal is to be an international Science Commons, not a UScentric life-sciences commons," he says.

http://creativecommons.org/projects/science/ proposal

\section{WHO seeks system for tracking global clinical trials}

\section{Erika Check, Washington}

The World Health Organization (WHO) hopes to earn international support next week for a far-reaching plan to set up a global tracking system for clinical trials.

The WHO will solicit support for the tracking system at its Ministerial Summit on Health Research, to be held in Mexico City on 16-20 November. WHO officials are proposing to establish an Internet portal that will give easy access to clinical-trial registries around the world. They also want to create a unified system for assigning unique identifiers to trials.

These measures are intended to reduce the duplication of trials and make it easier for medical researchers, the public, journal editors and governments to track them. By taking the lead on a global registry, it also hopes to set minimum standards for what information should be included in clinicaltrial registries.

"This is a good idea that's been languishing for years and has been revitalized in the past six months," says Timothy Evans, assistant director-general for evidence and information policy at the WHO in Geneva. "Given the groundswell of interest, we're very keen to get this trials registration into global practice as soon as possible."

Patient advocates and health researchers have long pushed for clinical-trial registries, saying they provide a fuller picture of the performance of drugs and devices in trials than that given by the often-favourable results published by manufacturers.

Registries have only recently started to receive strong support, however, following scandals such as the year-long controversy over the possible increased suicide risk among children taking antidepressants called selective serotonin reuptake inhibitors (SSRIs), which raised the profile of the issue. The US Food and Drug Administration said last month that SSRIs increase the risk of suicide in children, but based its conclusions on unpublished data that had been unavailable to the public.

"The reason this has caught on now is the SSRI issue," says Kay Dickersin, an epidemiologist at Brown University's Center for Clinical Trials and Evidence-based Healthcare in Providence, Rhode Island, who has been working with the WHO to

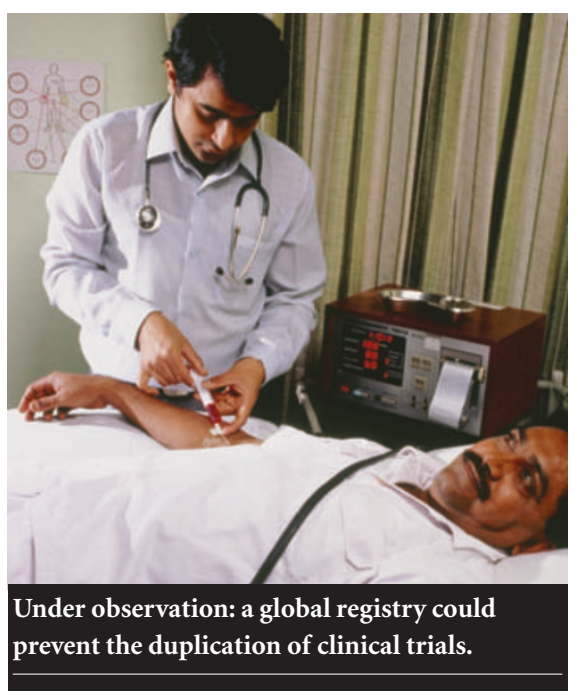

develop plans for a global registry. "It has captured the public imagination."

But implementation of the WHO's global tracking system would face many obstacles, including financing - particularly for the incorporation of developing countries' clinical-trial data. The organization will find out in Mexico City next week how many nations back the concept. 